Article

\title{
Assessment of Comprehensive Effects and Optimization of a Circular Economy System of Coal Power and Cement in Kongtong District, Pingliang City, Gansu Province, China
}

\author{
Suocheng Dong ${ }^{1}$, Zhe Wang ${ }^{1,2}, \mathrm{Yu} \mathrm{Li}^{1}{ }^{1}$, Fujia Li ${ }^{1, *}$, Zehong Li ${ }^{1}$, Feng Chen ${ }^{1,2}$ and Hao Cheng ${ }^{1}$ \\ 1 Institute of Geographical Sciences and Natural Resources Research, Chinese Academy of Sciences, \\ Beijing 100101, China; dongsc@igsnrr.ac.cn (S.D.); wangzhe.11s@igsnrr.ac.cn (Z.W.); liy@igsnrr.ac.cn (Y.L.); \\ lizehong@igsnrr.ac.cn (Z.L.); chenf.15s@igsnrr.ac.cn (F.C.); chengh.12b@igsnrr.ac.cn (H.C.) \\ 2 University of Chinese Academy of Sciences, Beijing 100049, China \\ * Correspondence: lifj@igsnrr.ac.cn; Tel.: +86-10-6488-9842
}

Academic Editors: Giuseppe Ioppolo and Marc A. Rosen

Received: 6 January 2017; Accepted: 22 April 2017; Published: 11 May 2017

\begin{abstract}
The idea of a circular economy (CE), which differs from traditional linear economy with a high consumption of natural resources and pollution, has captured much interest and attention. This paper uses a CE system of coal power and cement in Kongtong District, Pingliang City, Gansu Province, China as a case study to analyze the comprehensive effects of CE paradigm. Our simulation results, based on system dynamics (SD) modeling, infer that the transformation of manufacturing towards a $\mathrm{CE}$ system can prominently help coal power and cement enterprises reduce waste emission and increase economic profits. Through solid waste exchanges, a power plant can achieve over RMB 80 million of additional revenue per year at the highest level. CE also contributes to the reduction of regional pollution, saves mineral resources, and improves the atmospheric environment, an accumulated total of 14.11 million $t$ of natural gypsum and 22.67 million $t$ of coal can be saved. This sets a promising example for coal power and cement plants worldwide. Effective regulatory measures and further optimization towards a circular economy system are essential in maintaining the stable development of a CE system due to the risk of surplus production of upstream industries and other defects.
\end{abstract}

Keywords: circular economy; China; coal power; cement; system dynamics; effects assessment

\section{Introduction}

The concept of a CE was first put forward by Pearce and Turner, two British environmental economists [1]. Unlike a traditional linear economy of take-make-dispose with high consumption, emission, and pollution, a CE system is regarded as a closed system, much like a natural ecological system in which all elements are circular and the production departments in a shared circular cycle can form an industrial symbiosis mimicking the natural food cycle [2,3]. The distinguished principles of "Reduce, Reuse, and Recycle" (3Rs) are the basic theoretical philosophical and principles behind CE. The main content of CE is to reap economic, ecological, and social benefits through eco-design in the manufacturing process and further realize the goal of sustainability [4-7].

In recent years, most worldwide case studies concerning $\mathrm{CE}$ can be classified into four scales: national, regional, industrial, and enterprise. Studies on national or regional scales have been mainly focused on assessing the development of CE through the analysis of key indicators [8-10], and summarizing performance and problems during the developing process of $\mathrm{CE}$ in a certain country or region [11-13]. Studies on an industrial scale mainly discussed the achievements of cleaner 
production and economic benefits through the design of CE systems and analyzed problems, which covered industries such as papermaking [14], building materials [15-18], metals [19,20], chemicals [21], logistics [22], etc., and the industrial symbiosis between the various departments in a certain industrial park [23-25].

On the whole, these studies explored the connotations and realization path of CE from different perspectives; however, most studies focused more on macro-scale analysis and less on the quantitative analysis of the process of CE system on enterprise scale. Therefore, by using the case of a CE system of coal power and cement in Kongtong District, Pingliang City, Gansu Province, China, this paper built an SD model to simulate the comprehensive effects of a CE system on coal power and cement, before making recommendations to improve system performance.

Coal power plants are widely distributed around the world, especially in regions with abundant coal resources. Among the various kinds of power generation, coal power has occupied over $40 \%$ of the global total from 2010 and, in China, this share reached 80\% [26,27]. Coal power plants have the advantage of low costs; however, severe issues of unsustainability such as the consumption of fresh water and pollution caused by fly ash, desulfurization gypsum, and other solid waste affects many cities without supporting industries to reuse the solid waste. In contrast, the example set by Kongtong District provides a promising example for the sustainable development of the coal power and cement industries. However, market risks are big disadvantages for CE system of coal power and cement, and should not be ignored. Hence, for further optimization and popularization of a CE system in the coal power and cement industries, the comprehensive effects of CE system need to be quantitatively studied.

\section{Case Study}

Kongtong District is located in Northwest China (Figure 1), and has abundant mineral resources such as coal, limestone, gypsum, clay, as well as well-developed industries of coal mining, coal power, and the manufacture of building materials. In China, CE development has been motivated by national policy and planning, thus, in the past five years, Kongtong has attracted significant amounts of capital in the field of CE to build a host of new projects using high technology to achieve certain benefits. Key enterprises include: (1) The Huaneng Pingliang Thermal Power Plant (HPTPP) (Pingliang, China), which belongs to the China Huaneng Group and has the largest capacity installed (2.4 million kW) in Northwest China; and (2) Conch Cement Ltd. (Wuhu, China), the largest cement brand in China. The key categories of industry in this study highlights the important status of Pingliang's industrial structure (Figure 2).

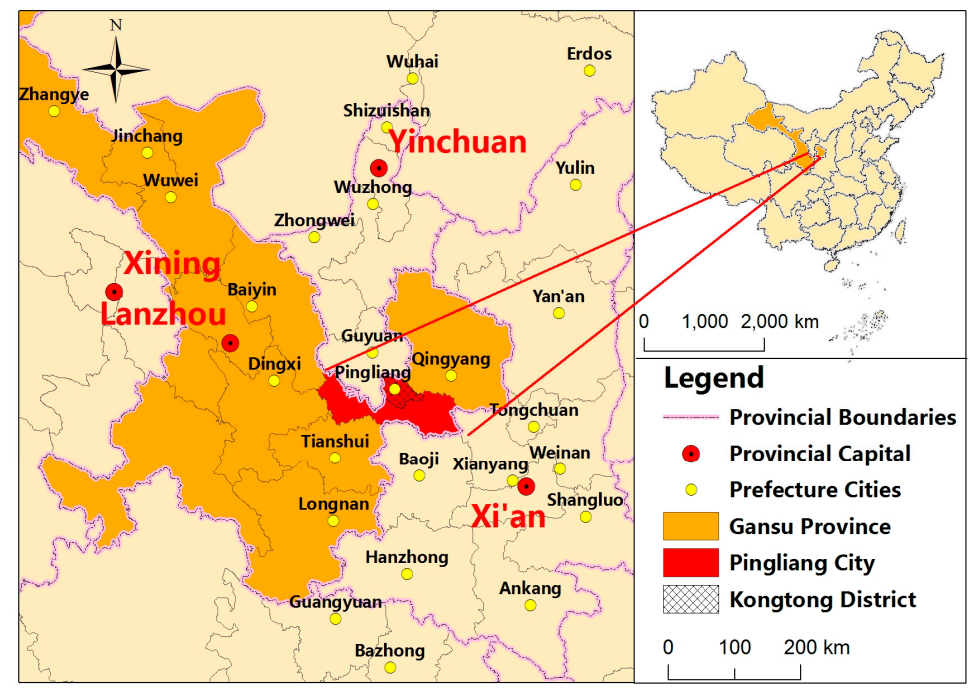

Figure 1. The location of Kongtong District, Pingliang City, Gansu Province, China. 


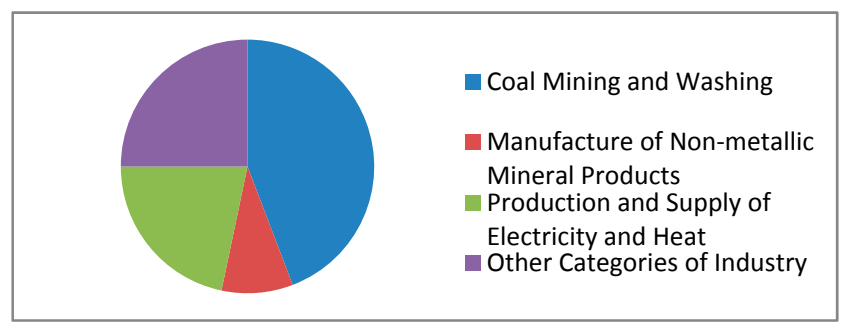

Figure 2. The proportion of the production value of key categories of industry in Pingliang's industrial structure.

\subsection{Successes Achieved by a CE System of Coal Power and Cement}

To show the differences between the traditional linear manufacturing paradigm and a fully implemented and well-run CE manufacturing system have been illustrated (Figure 3). Negative effects have been removed and positive effects have been achieved through a move towards a CE system.

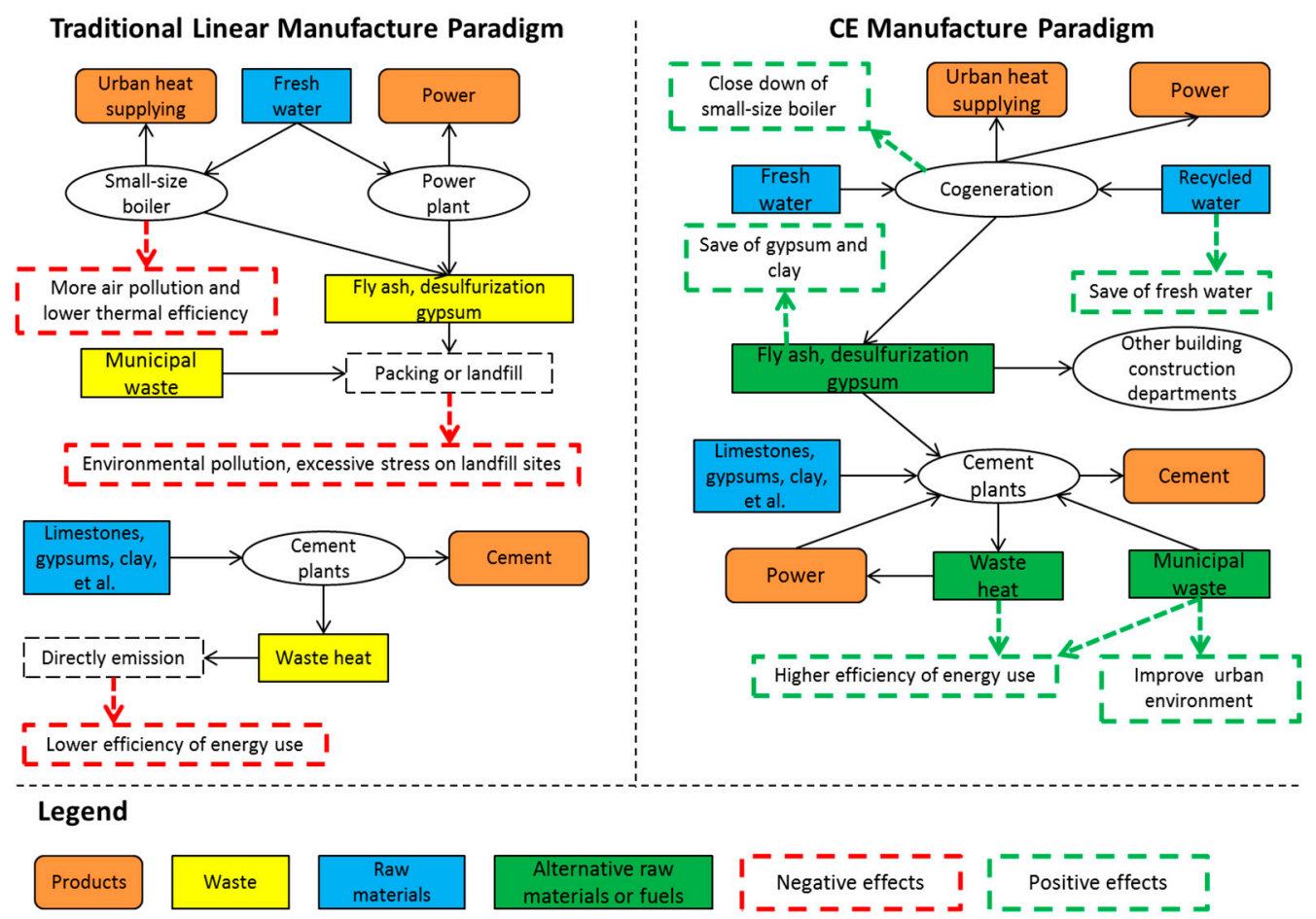

Figure 3. A comparison between past and present manufacturing paradigms.

2.1.1. Circular Utilization of Solid Waste between Coal Power Plants and Building Materials Industries

Fly ash has a high use value in the construction and building materials industries. Following the rise of construction and the building materials industries in Pingliang, the demand for fly ash and desulfurization gypsum exceeds supply, which thoroughly solves the issue of solid waste pollution caused by coal power.

Dry and wet fly ash produced by HPTPP reached the second level of the National Standards of China with a fineness less than $20 \%$. Desulfurization gypsum has the same ingredients as natural gypsum, but has a higher purity, which saves costs in the grinding process during cement production. 


\subsubsection{Utilization of Waste Heat and Height Difference Potential in Cement Plants}

According to survey data from Conch Cement Ltd., a pure low-temperature waste heat-power generation system with an installed capacity of $2 \times 7.3 \mathrm{MW}$ went into operation in 2011 and provides $32.18 \%$ of total power usage. During the process of limestone mining, a height difference potential power generation system can provide $2.15 \%$ of total power use through transmission belts with a height difference of $230 \mathrm{~m}$. In 2014, two cement plants in Kongtong consumed only $94.28 \mathrm{~kg}$ of standard coal per capita, which was far below the national average level $(136 \mathrm{~kg})$.

\subsubsection{Combined Heat and Power Generation and Reclaimed Water Utilization}

A traditional distributed heat supply may easily cause dust emissions in winter, but also has a lower thermal efficiency. In comparison, the biggest advantage to the pattern of cogeneration is enhanced utilization efficiency of fuel and improvements in urban air quality.

In 2010, the latest sewage-treatment system in the coal power plant took waste water from the city area and the plant as a resource to produce recycled water. The present consumption of reclaimed water is $250 \mathrm{t} / \mathrm{h}$, which reduces the consumption of fresh water. The purity of the reclaimed water does not reach the standards of boiler feed-water, but is satisfactory for use as cooling water and supplementary water for machine sets mainly because the concentration of suspended substance of reclaimed water is less than $30 \mathrm{mg} / \mathrm{L}$ and does not reach $5 \mathrm{mg} / \mathrm{L}$.

\subsubsection{Taking Municipal Waste as Alternative Fuels for Cement Manufacture}

Greatly increased municipal waste leads to higher treatment difficulties and costs. Generally, disposal methods of municipal waste often include landfill, incineration, compost, and methane generation. According to the National Bureau of Statistics of China, in 2014, 60.15\% of municipal waste was disposed through landfill. Municipal waste contains large quantities of organic fuel with a high heat value. Thus, if waste sorting costs are too high, incineration is an appropriate method that has been adapted to regional realities. Furthermore, a cement kiln co-disposal incineration system (CKCDIS) can additionally solve the problem of dioxin pollution effectively through a disposal process of homogenizing, crushing, and gasifying. After decomposing, hazardous substances can be assimilated by cement clinker. Incombustibles ultimately become slag and can be utilized as alternative raw materials for cement manufacture.

In 2014, a CKCDIS (with a disposal capacity of 100,000 t) built by Conch Cement Ltd. was put into operation, and has helped to avoid land and groundwater pollution caused by waste landfill. According to survey data, heat per capita can reach over 1000 kilocalorie per $1 \mathrm{~kg}$ waste, which can be utilized as an alternative fuel to save coal.

\subsection{Market Risks the CE System of Coal Power and Cement May Face}

In China, the coal power industry faces a severe market downturn as China's economic development and consumption of power slows down. As newly-built coal power projects are still large-scale, there is a severe problem of excess production capacity [28], as well as an obvious regional imbalance of supply and demand due to China's vast territory. Areas with abundant coal resources, such as Kongtong, often have lower levels of manufacture and living standards, which leads to lower power consumption [29]. Furthermore, as there is rising market competition against coal power due to the strong encouragement of non-fossil fuel based energy such as hydroelectric power, photovoltaic power, and wind power generation, the amount of power generated by Kongtong reduced sharply in 2015 and reached over 6 billion $\mathrm{kWh}$, which only occupied about $50 \%$ of production capacity despite the power generation process also achieving cleaner production targets through the method of strict desulfurization, denitration, and dedusting. Thus, one question that still remains is how to sustainably develop a CE system in the face of adverse market situations. 


\section{Methodology and Data Sources}

SD is a methodology and mathematical modeling technique used to frame, understand, and discuss dynamic behaviors and issues of complex systems by setting variables with positive and negative feedback, and is integrated by management science and computer simulation technology [30,31]. The comprehensive effects of an industrial symbiosis system can be quantitatively analyzed based on an interpretation of a situation and ecological, social, and economic subsystem trends in the real world through the introduction of SD into the field of CE [32-34]. Vensim-software developed by Ventana Systems Inc. (Harvard, America), USA-can provide a graphical modeling interface with stocks, flows, and causal loop diagrams for researchers to conveniently build SD models. Hence, this paper selected Vensim as the tool for modeling a manufacture CE system in Kongtong.

Parameters of each variable in the SD system were from enterprise and government survey data and local statistics yearbooks. For quantitatively studying a CE system of coal power and cement at an enterprise scale, we carried out field research in February 2015 and July 2015. Through interviews with leaders and technicians in key enterprises and government staff in departments relating to coal power and cement industries, detailed information and data on the manufacture process were achieved and includes four parts: (1) The production flow chart; (2) the introduction of progress of manufacture transition towards CE; (3) the utilization amounts of different categories of raw material, energy, fuel, products, waste; and (4) the approximate price of products and raw materials.

\section{Model Description}

The SD model contained one coal power plant, HPTPP, and two cement plants, Conch Cement Ltd. and Qilianshan Cement Ltd. (Pingliang, China). In the SD model, the time step was set as year, initial time and final time were split into 2014 and 2025. The performance period of the model crossed China's 13th and 14th Five Year Plans. In Figure 4, the variables are connected by arrows, which indicates causal relationships in the SD system where the variable before an arrow affects the variable behind the arrow. The market demand of products $\rightarrow$ yield $\rightarrow$ demand of materials or fuel $\rightarrow$ supply-demand difference (SDD) is the basic causal chain of the system.

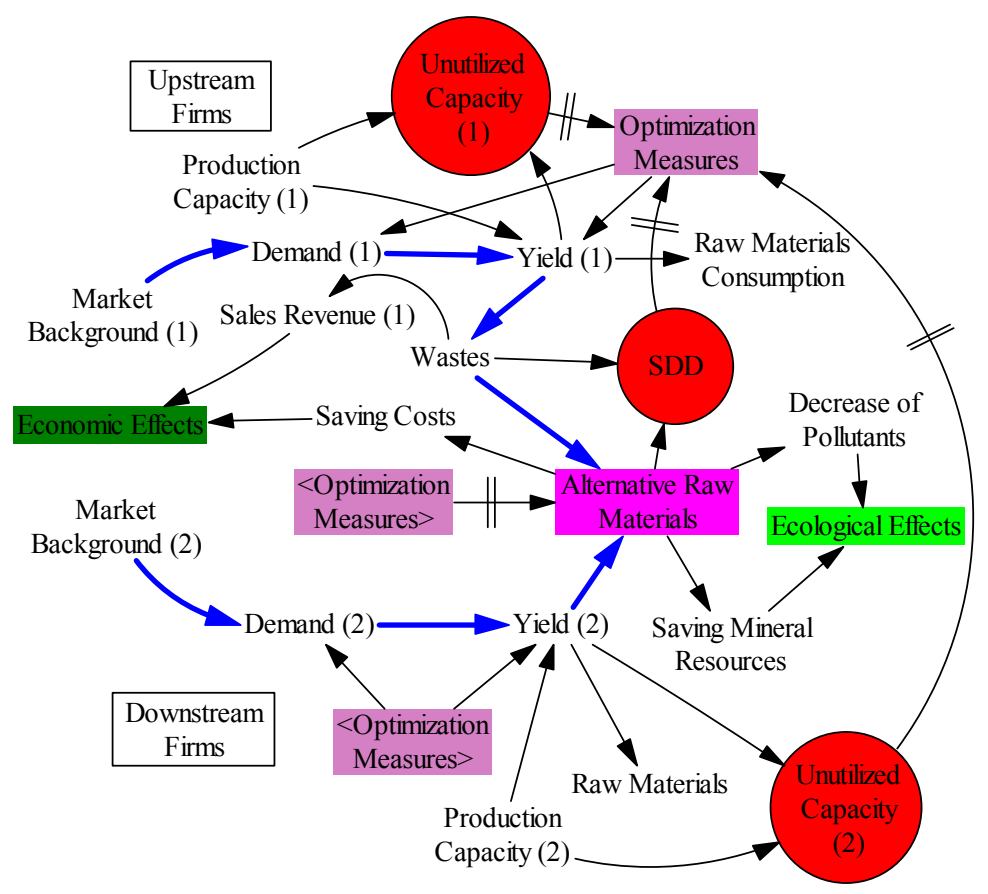

Figure 4. Logical framework of the SD model. 


\subsection{Sub-System of Operation Structure}

Based on the logical framework presented in Figure 4, the operation structure of a CE system of coal power and cement can be framed through the Vensim software. In Figure 5, the power yield of HPTPP affected total consumption and further affected the amount of solid waste, including fly ash, desulfurization gypsum, and slag. Furthermore, the cement demand affects the cement yield and further affects the demand of alternative materials. Thus, the SDD of key recycling waste needing to be balanced is a key conflict in the system as a short supply of key materials can lead to instability of industrial symbiosis and excessive supply, which means high disposal costs of solid waste. In the system, the amount of fly ash and slag results from the coal consumption of the HPTPP, as well as a portion of slag produced by CKCDIS. The amount of desulfurization gypsum results from the amount of sulfur content in coal and limestone consumption. Considering the difficulty of obtaining data, we assumed that there was a $70 \%$ of fly ash from HPTPP sold to other building departments.

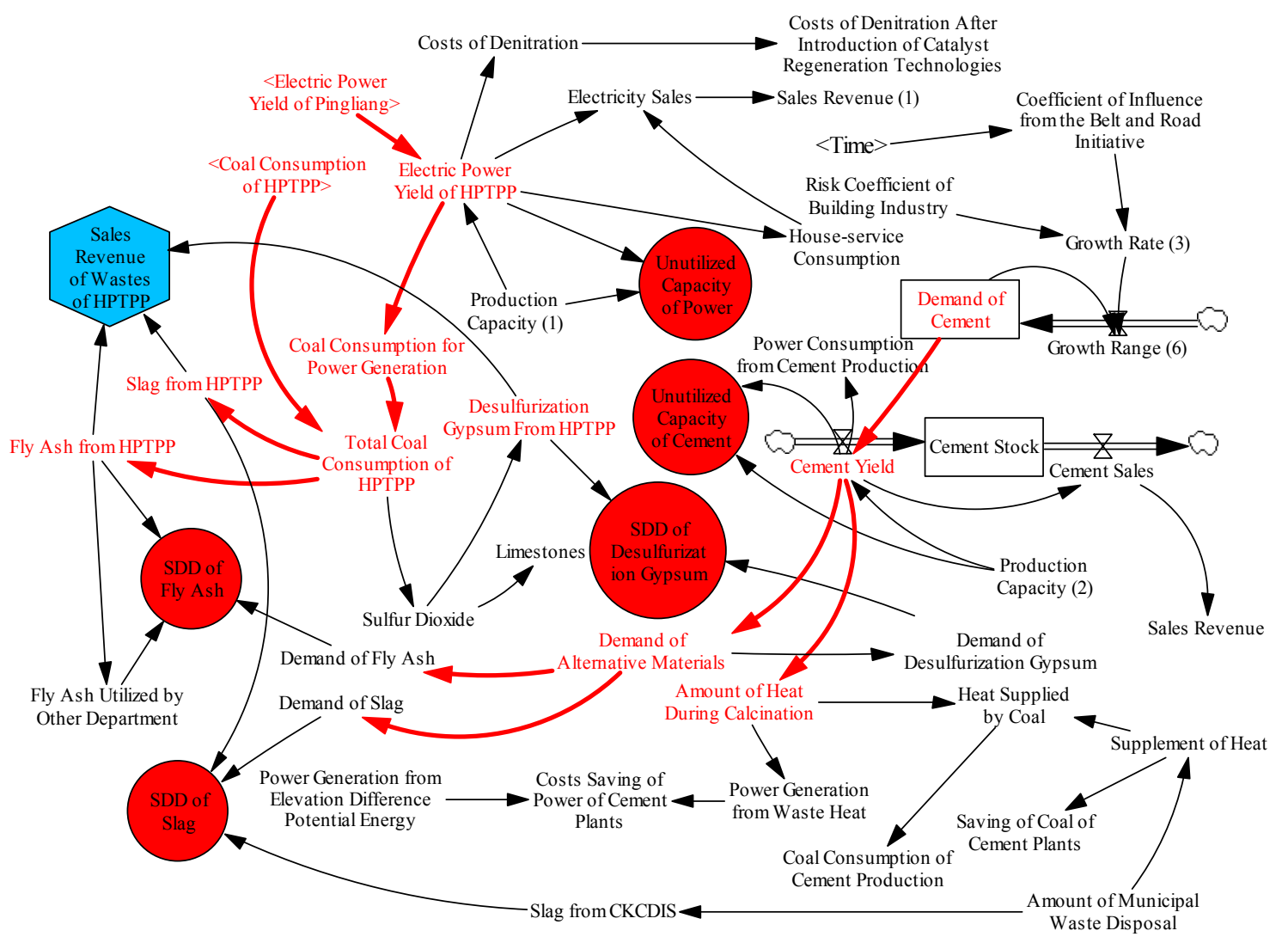

Figure 5. Operation structure of the CE system.

\subsection{Sub-System of Ecological and Economic Effects}

The main positive ecological effects include saving mineral resources and reducing pollutants and greenhouse gasses (illustrated as variables in Figure 6). In the system, a decrease in emissions and savings on coal consumption were calculated through comparing data in a practical scenario that the CE paradigm has already been implemented and a hypothetical scenario where a traditional pattern would not have been improved. Based on survey data, we set the sulfur and ash content proportion of coal Kongtong utilized separately as $0.5 \%$ and $11 \%$, efficiency of combustion, desulfuration, and dedusting of traditional small-size boilers as $72,97.8$, and $16.7 \%$, respectively. The carbon emissions from coal burning were calculated by the formula $\mathrm{E}=\mathrm{EC} \times \mathrm{EF} \times \mathrm{f}$ in which $\mathrm{EC}$ is the consumption of coal, EF is the coefficient of carbon emission of coal, and $\mathrm{f}$ is the coefficient of standard coal (0.7143). EF was set as 0.7266 [35]. Carbon emissions from cement production were also divided into two 
categories: carbon emissions from the process of calcination, and carbon emissions caused by coal burning. The first category occupied nearly $50 \%$ of the total amount of carbon emission resulted from the decomposition reaction of $\mathrm{CaCO}_{3}$, thus limestones could be replaced by alternative raw materials containing $\mathrm{CaO}$ content, which can dramatically reduce carbon emissions.

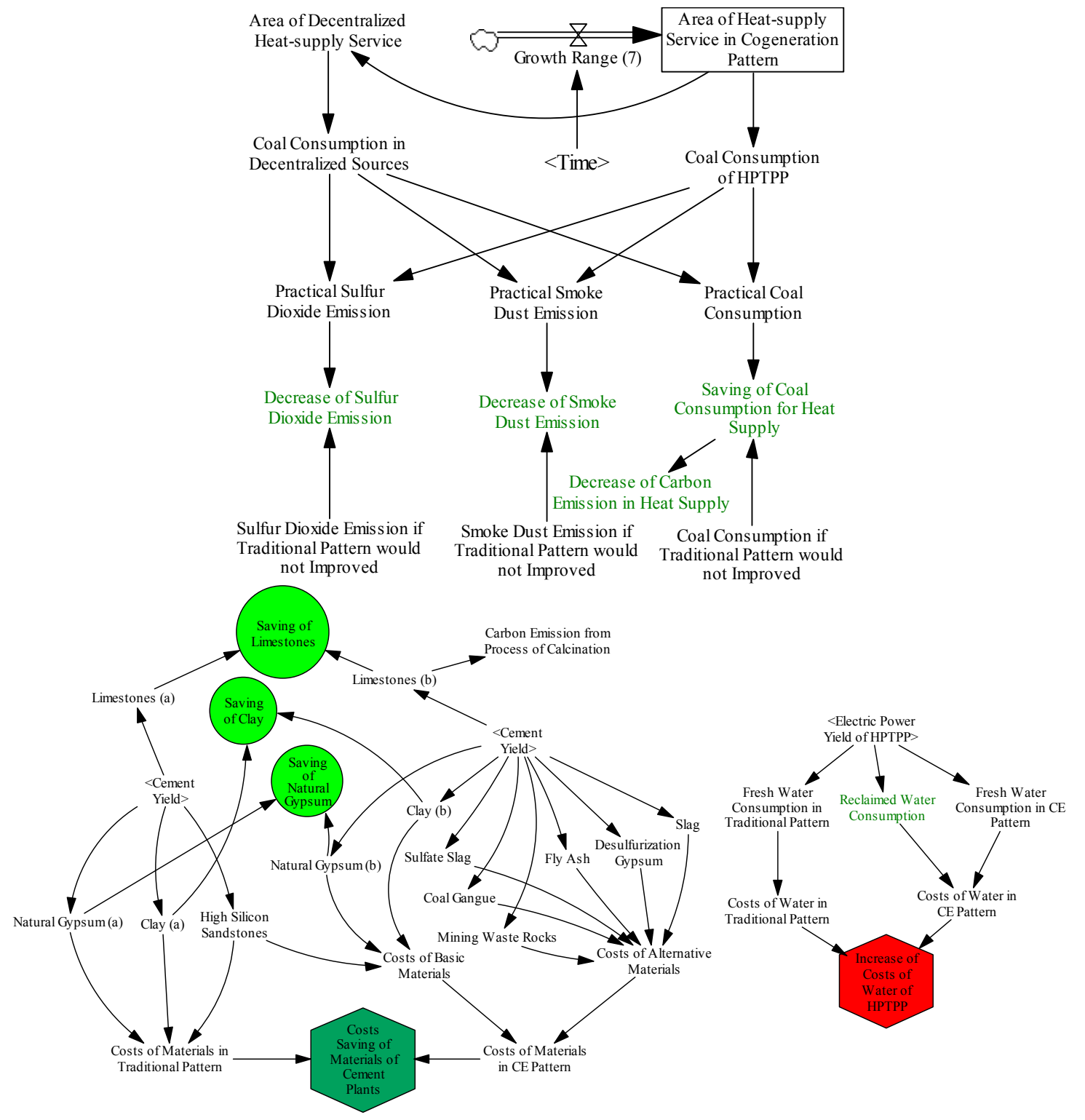

Figure 6. Ecological and economic effects of the CE system.

Compared to a traditional manufacturing pattern, apart from product sales revenue, positive economic effects include additional benefits such as the reuse of materials and energy, sales revenue of the by-products. Negative effects are embodied in increased costs caused by higher costs of recycled water treatment and denitration based on selective catalytic reduction catalysts. Like the ecological effects calculation mentioned above, both positive and negative economic effects can also be calculated by comparing data in the CE paradigm and hypothetical scenario that traditional patterns would not change. To simplify the simulation, we assumed that the raw material ratio of cement and the prices of raw materials, products and energy would not vary dramatically during the run time of the model. 


\subsection{Sub-System of Market Demand}

\subsubsection{Sub-System of Market Risks and Solutions Already Taken}

In this subsystem, we assumed that the amount of power produced by HPTPP totaled $56.43 \%$ of Pingliang during the performance period and that this proportion would not change observably (Figure 7). In 2014, the power delivered outside (PDO) was 79.9\% of the amount from Pingliang and a paramount influence factor to the HPTPP. Furthermore, local power consumption can usually be attributed to residents, manufacturing, tertiary industries, and so on, which can be predicted based on statistics.

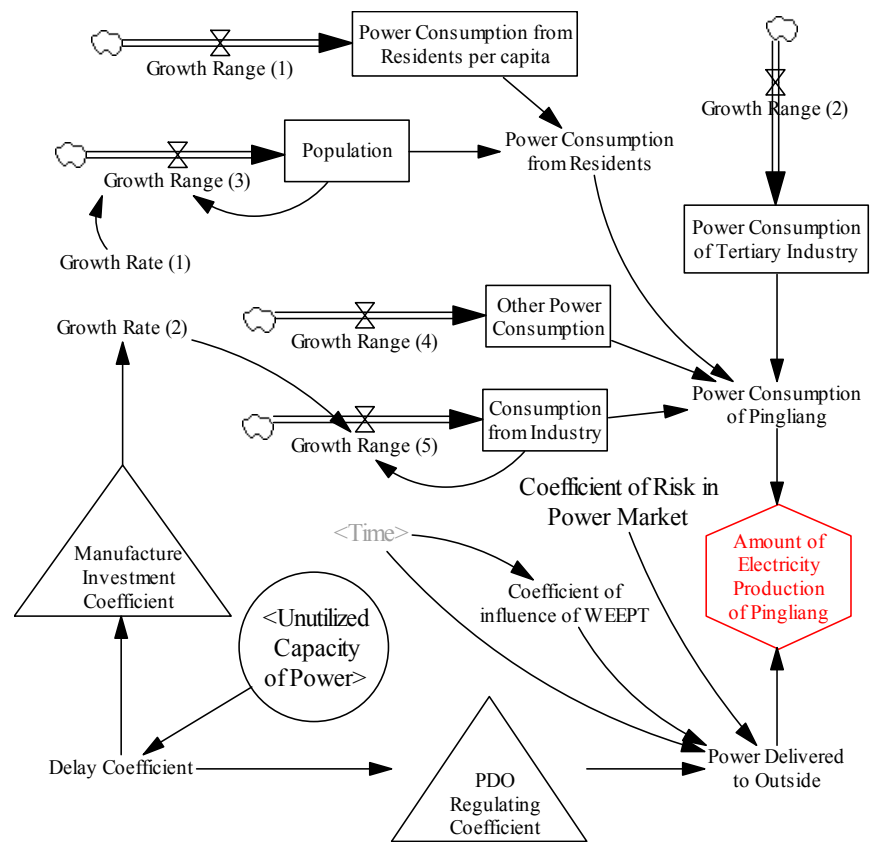

Figure 7. Scenario simulation of power production in Kongtong.

Unutilized capacity, one of the key conflicts in the system, affects the stability of the whole system and results in regulation regarding PDO and manufacturing investment (Figure 5). Local government may be stimulated to strive for more chances to attract manufacturing investment and PDO to make up for HPTPP's loss. Therefore, we set PDO regulating coefficients, manufacture investment coefficients, and a delay coefficient of two years, to simulate the government's action and the time difference between decision-making and projects being put into effect.

The West-East Electricity Transmission Project (WEETP) can relieve the power deficit in East China, and also exploit the advantages of areas with affluent power resources such as Kongtong. Thus, the coefficient of WEETP was set to simulate a scenario where Pingliang would be absorbed into the WEETP, where PDO can increase dramatically. Considering the progress of relative power transmission projects, we assumed two scenarios in which the coefficients of WEETP were 0 initially and increased individually from 2019 and 2023. Furthermore, the risk coefficient was divided into low-risk and high-risk scenarios, to simulate the difficulties and uncertainty Kongtong faces in striving for PDO.

The demand of cement is affected by multiple elements including the development of the building industry, macro-economic situation, and urbanization, etc., so it is hard to achieve an accurate prediction of the demand of cement. Accordingly, considering the stability of the cement market in Pingliang and surrounding areas, we set the random risk coefficient of the building industry in the system to simulate possible narrow fluctuations of cement production (Figure 5). 
In addition, the strategy of the Belt and Road Initiative proposed by China focuses on the connectivity and cooperation among countries in Asia and Europe, gives rise to the wave of infrastructure construction in Northwest China and countries along the Silk Road Economic Belt, which will stimulate the development of the cement industry to some extent. Thus, we set a rising coefficient to simulate this effect.

\subsubsection{Sub-System of Demand of Municipal Heat}

The amount of heat supply was simulated based on the specialized planning of the concentrated heat supply of Pingliang. The heating supply area of cogeneration in Kongtong reached 8 million $\mathrm{m}^{2}$ in 2012 and will reach 23.5 million $\mathrm{m}^{2}$ in 2016 according to planning.

\section{Results and Analysis}

\subsection{Analysis on Ecological Effects}

Profit from the implementation of the CE paradigm, consumption of clay and natural gypsum can be reduced to $68.3 \%$ and $73.7 \%$, respectively, through the utilization of alternative raw materials. During 2014-2025, the accumulated savings of clay and natural gypsum will reach 2.48 million $t$ and 14.11 million $t$ (Figure 8). The accumulated saving of limestones is only 236.3 thousand $t$ due to low $\mathrm{CaO}$ content in alternative raw materials, $3.2 \%$ in fly ash and $2.8 \%$ in slag. However, compared to cases introduced by [36], the consumption of limestone in Kongtong is relatively high.
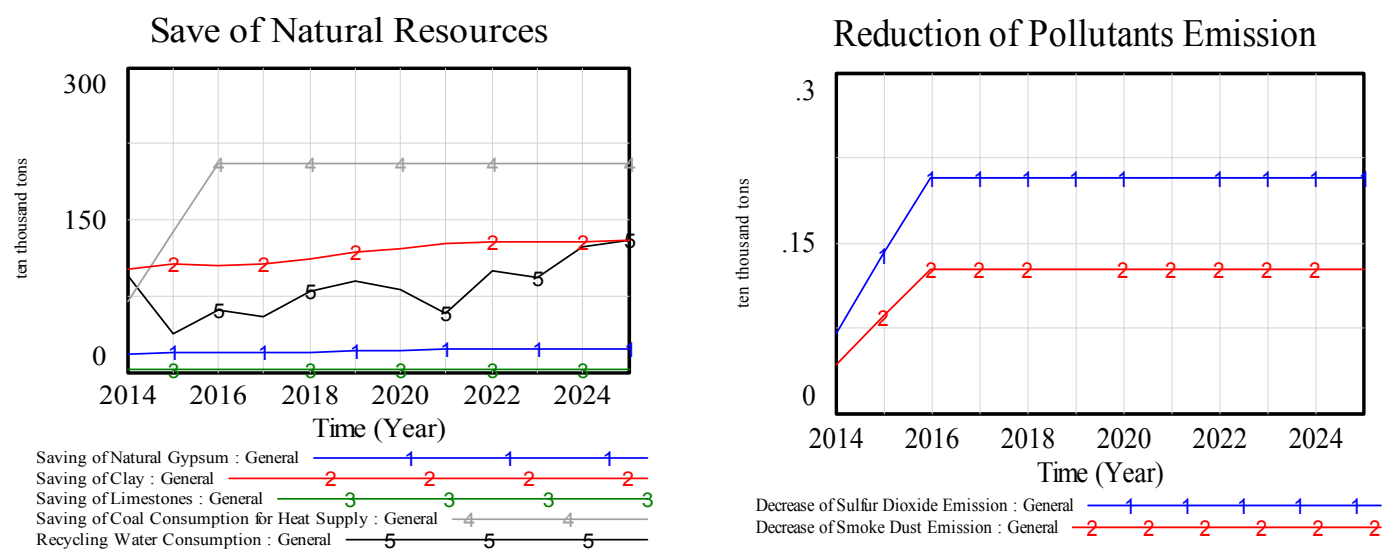

Carbon Emission from Process of Calcination

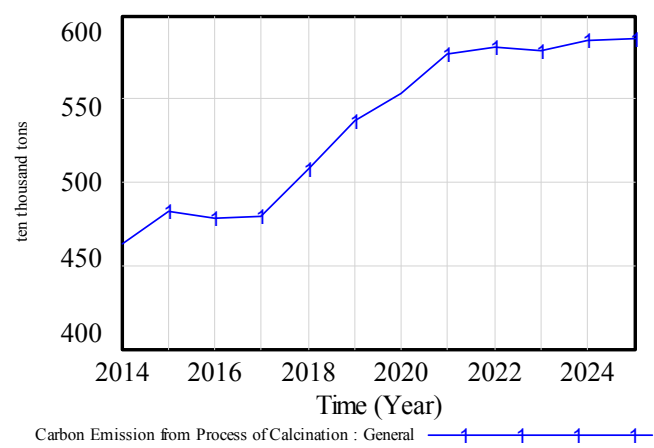

Figure 8. Simulation of ecological effects of the system (Unit: $10^{4} \mathrm{t}$ ).

The combined heat and power generation facilities have more advanced technical standards on desulfuration and dedusting and higher coal combustion efficiency, thus, the advantages are reflected in reducing coal consumption and pollution compared with traditional small-size boilers. These ecological effects will reach a peak in 2016 when areas of heat supply reach 23.5 million $\mathrm{m}^{2}$ (Figure 8). 
During 2014-2025, the accumulated savings of coal will reach 22.67 million $\mathrm{t}$, the reduction of $\mathrm{SO}_{2}$ and dust will reach 22.8 and 13.9 thousand $t$, respectively, which will positively improve the air quality of Kongtong. However, heat loss caused by the direct emission of $30^{\circ} \mathrm{C}$ steam in HPTPP should not be ignored.

By harmlessly disposing of all the municipal waste of Kongtong, CKCDIS assists Conch Cement Ltd. to save $794 \mathrm{t}$ of coal, which was equal to $0.2 \%$ of the coal consumption of Conch Cement Ltd. As a result, a decrease of $519 \mathrm{t}$ of carbon emissions can be achieved and this effect will reach a peak in 2025 along with the increase of cement yield. CKCDIS can also save an accumulation of $0.2 \mathrm{~km}^{2}$ land during 2014-2025.

\subsection{Analysis on Economic Effects}

The economic benefits achieved by the HPTPP and cement plants through recycling and reuse are illustrated in Figure 9. The sales revenue of waste from HPTPP resulted from the power yield, so two scenarios were simulated which considered risk and WEETP. It was obvious that regardless of these scenarios, the sales revenue of solid waste from the HPTPP will grow in general. The savings in the cost of power from cement plants is also a high-level profit from waste heat and the height difference in energy power generation will make up $30 \%$ of power consumption. The peak of sales revenue will be achieved in 2022 or 2025 due to increased power yield.
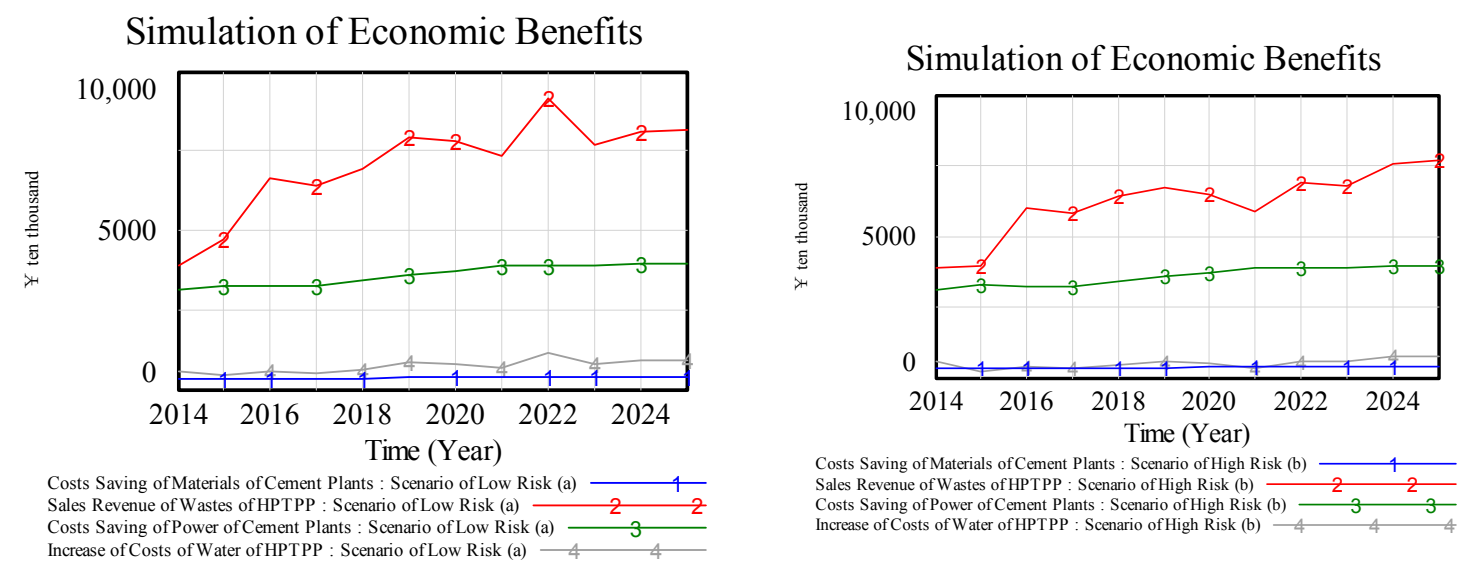

Figure 9. Simulation of economic benefits of the system (Unit: RMB $10^{6}$ ).

The higher cost of recycled water in HPTPP, approximately RMB 10 per ton is equal to 2.5 times the price of fresh water for coal power in the Gansu Province (RMB 0.003/kWh), is a negative economic effect of the system, but can be made up by revenue from the sale of waste.

Under legal pressure from environment protection departments, the high costs of the denitration process bring difficulties to the HPTPP. In 2014, the costs of denitration reached RMB 0.23 billion based on the unit price of RMB $0.025 / \mathrm{kWh}$, and the maximum will reach RMB 0.45 billion per year, which is another negative economic effect that should be optimized.

\subsection{Analysis of Supply and Demand Conflicts of Recycling Wastes}

In the CE system, fly ash and desulfurization gypsum are already key materials of the down-stream building materials industry. However, the low power yield results in an unfavorable situation that recycling waste cannot meet the demand of downstream enterprises, which will result in a greater consumption of natural resources by downstream enterprises. Fortunately, as seen in Figure 10, the benefits from a nationally supported project, even under the worst scenario, will be improved by growth in power yield and the SDD will become positive. Peak value will appear in 2022 or 2025 because of peak value of power yield shown in Figures 11 and 12. It should be noted that an 
oversupply of fly ash may appear after the situation of the coal power industry is improved. At that time, a stockpile of fly ash will bring negative effects to the system.
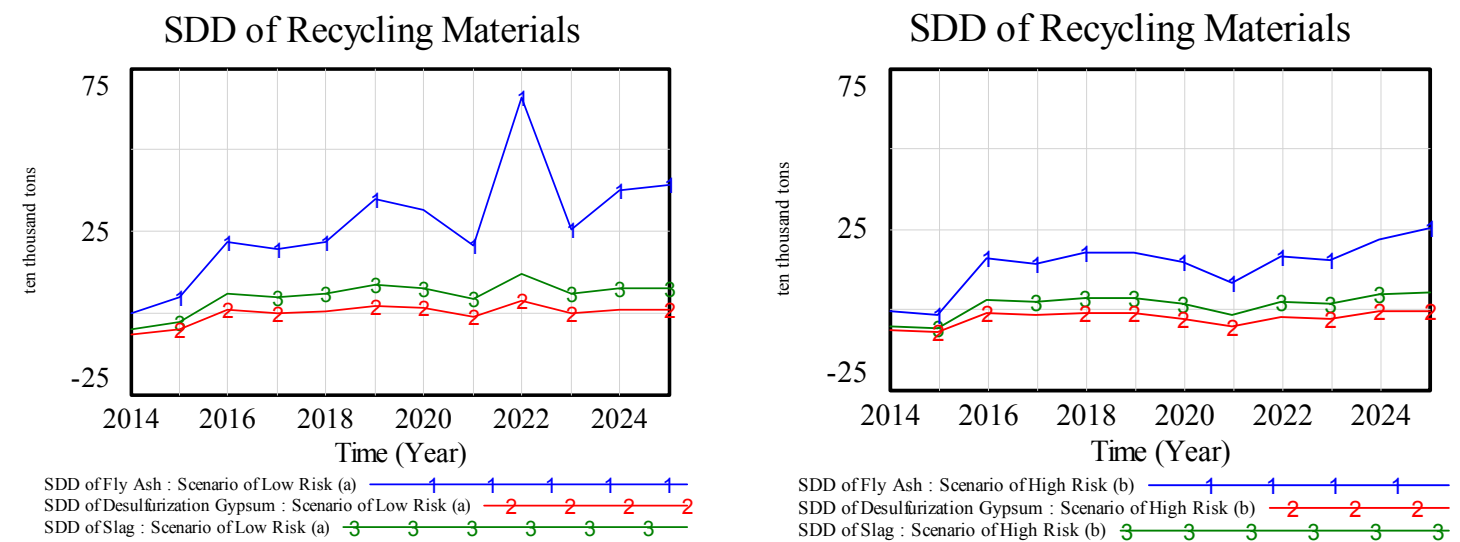

Figure 10. Simulation of SDD of fly ash, desulfurization gypsum, slag under scenario of WEETP put into practice in 2019 or 2023 and high or low risk of power market (Unit: $10^{4} \mathrm{t}$ ).

Simulation of Electric Power Yield

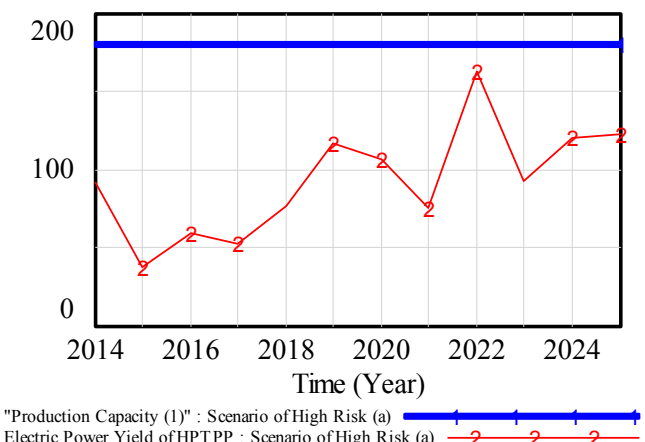

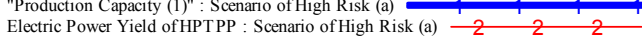

\section{Simulation of Electric Power Yield}

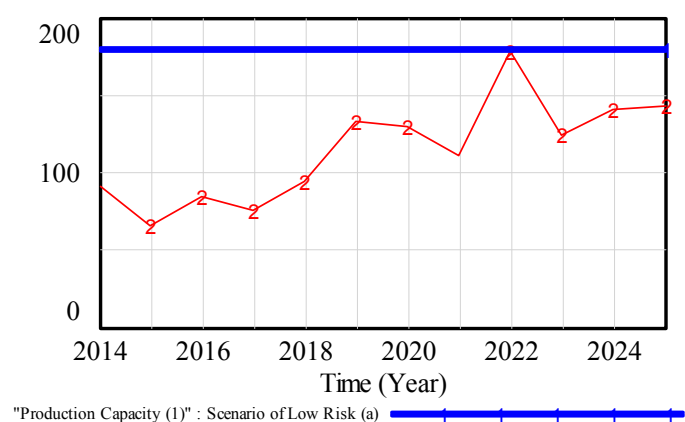

\begin{tabular}{l} 
"Production Capacity (1)" : Scenario of Low Risk (a) \\
Electric Power Yield of HPTPP : Scenario of Low Risk (a) $12+2$ \\
\hline
\end{tabular}

Figure 11. Simulation of power yield under scenario of WEETP put into practice in 2019 and high or low risk of power market (Unit: $10^{8} \mathrm{kWh}$ ).

\section{Simulation of Electric Power Yield}

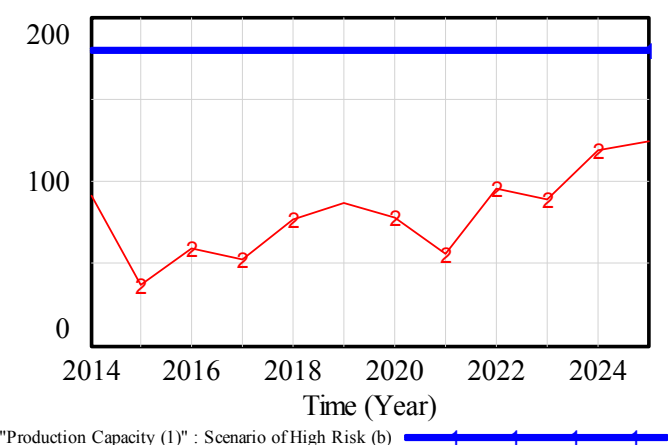

"Production Capacity (1)" : Scenario of High Risk (b)
Electric Power Yield of HPTPP : Scenario of High Risk (b) $2+2$
Simulation of Electric Power Yield

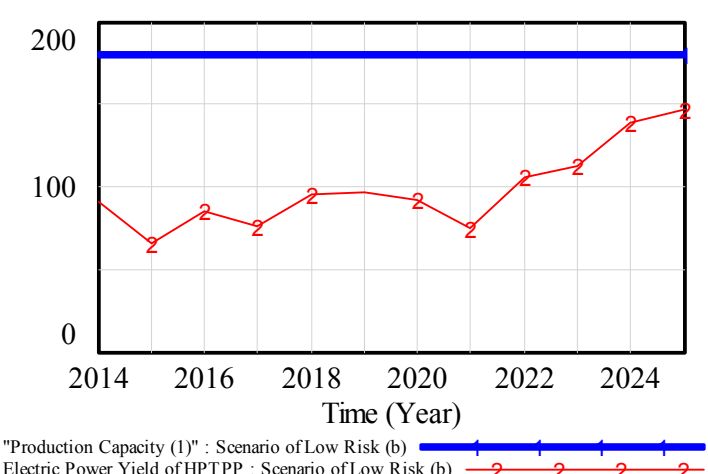

Figure 12. Simulation of power yield under scenario of WEETP put into practice in 2023 and high or low risk of power market (Unit: $10^{8} \mathrm{kWh}$ ). 


\subsection{Analysis on Market Risks}

Different scenarios of power production have been illustrated in Figures 11 and 12. The trends and peaks of lines of power yield are affected by coefficients about market risk and influence of WEETP explained in Section 4.3.1. If Pingliang is successfully absorbed into the WEETP before 2018, power yield will demonstrate a growth trend despite fluctuation, and the difference between production capacity and yield will shrink. Under a low-risk scenario, power yield will reach 13.2 billion $\mathrm{kWh}$ in 2019 and 17.8 billion $\mathrm{kWh}$ (peak value) in 2022. An increase of the risk coefficient will cause certain negative effects on power generation; however, even in a high-risk scenario power yield still can be kept at a healthy level by successful generation of opportunities for WEETP based on advantages of lower costs, capacity, and technology.

Next, we simulated a relatively pessimistic scenario where Pingliang is absorbed into the WEETP after years from 2018. Under this scenario, the difference between production capacity and yield will be kept at a high level, which will not be improved until 2023.

The simulation shows that the cement yield manifests a small decline from 2015-2017 and rises after 2017 from profits from the construction of infrastructure and the export of cement products stimulated by the Belt and Road initiative, and will reach production capacity in 2025 (Figure 13).

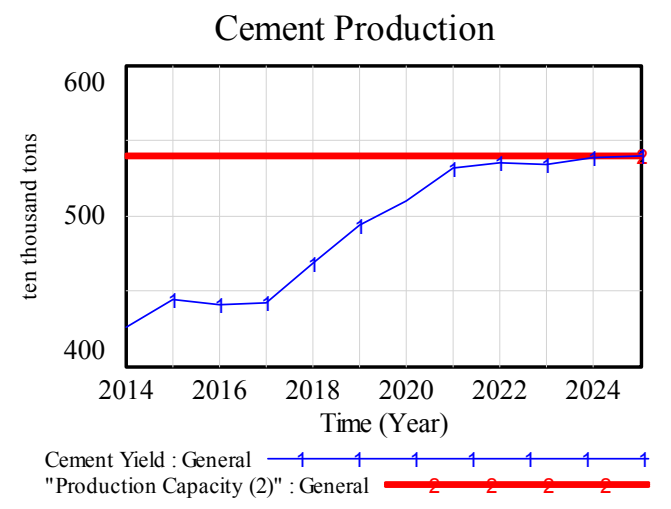

Figure 13. Simulation of cement production (Unit: $10^{4} \mathrm{t}$ ).

\section{Optimization Measures of Industrial Symbiosis System}

Based on the SD modeling results, this paper puts forward several optimization measures aimed at existing problems to further improve the ecological and economic effects of the CE system.

\subsection{Improving Waste-Heat Utilization of Coal Power Plant}

The low-grade waste heat utilization in the HPTPP is still at a low level. By considering the technical feasibility of taking waste heat from a heat pump system to supply high grade heat for residents, this may save more coal on the basis of combined heat and power generation. Other methods of reuse include the supply of heat for rural greenhouses and breeding tropical fish and fish fries through water with low grade heat.

\subsection{Extending Categories of Alternative Raw Materials and Fuels for Cement Production}

In combination with actual situation, the further reduction of carbon emissions from cement plants in Kongtong can reclaim CaO-rich waste, such as sewage sludge, demolished building materials, and waste concrete powder as alternative raw materials and waste tires, animal residues, waste oil, sewage sludge, and waste plastics as alternative fuels. If limestone consumption can be decreased by $25 \%$, an accumulated decrease of carbon emissions will reach 16 million $t$ during 2014-2025. Local government could also put forward stricter goals of carbon emission reduction to promote less reliance on limestone resources by cement plants. 
However, it should be emphasized that if hazardous waste, such as waste tires and waste oil, are used as alternative fuels in the cement industry, volatile heavy metal elements are hard to solidify in cement products so severe pollutant emission may occur. Thus, for Kongtong or other cities with cement industries, the emissions process has to be monitored more closely when high ratios of alternative fuels are used in cement plants, and the pretreatment of hazardous waste is essential to prevent potential environment risks.

\subsection{Promoting the Local Demand of Power through Introduction of Enterprises with High Power-Dependence}

The relatively lower prices of coal and power are advantages of Kongtong to attract industrial transfer from enterprises in developed areas of China. To guarantee smooth regulations regarding manufacturing investment illustrated in Figure 7, Kongtong has already introduced several manufacturing enterprises with high technology content to stimulate the local economy. For instance, the production line of Gansu Composite New Materials Ltd. (Pingliang, China) was initially located in Shanghai and has now moved to Kongtong for the cost savings in power. Industrial distribution should also be more reasonably planned to ensure that the power capacity of West China can be efficiently utilized, but also relieve the pressure of power supply in East China.

\subsection{Optimizing the Denitration Equipment of HPTPP}

If catalyst reactivation equipment is introduced, the large scale decrease of waste selective catalytic reduction (SCR) catalysts can be achieved and the costs of denitration of HPTPP can be reduced. Under a low risk scenario, the accumulated savings of denitration during 2014-2025 could reach RMB 0.13 billion, if the rate of cost reductions were set as $60 \%$, which is an empirical value acquired from survey data.

\subsection{Further Extending the CE System}

To solve the issue of the present short supply of recycling waste and the future possibility of an oversupply of fly ash, it is necessary to add new manufacturing departments to the CE system and extend the consumption channel of recycling waste. Presently, production lines of coal to methanol and coal to polypropylene are in the process of construction and advancement. When put into operation, the coal chemical industry could supply more alternative raw materials for the building materials industry. Building a production line of zeolite synthesized from fly ash, which can be utilized in the demercuration of coal gas, could be a new pathway for fly ash consumption for Kongtong. Furthermore, Beijing Baogui Stone Art Technology Ltd. (Beijing, China).—a distinguished example in field of CE-reuses solid waste in an upscale way by pressing fly ash to manufacture reproduced stones with high art content and added value. It is possible that Kongtong could positively cooperate with these types of art enterprises to enhance the value of solid waste to a higher level.

For the HPTPP, launching the projects of $\mathrm{V}_{2} \mathrm{O}_{5}$ reclaimation from waste SCR catalysts can not only help avoid further pollution, but also help the country save vanadium resources.

\section{Discussion and Conclusions}

This paper modeled the CE system of coal power and cement in Kongtong and quantitatively analyzed its operational structure and the ecological and economic effects using the SD method and Vensim software. The following conclusions have been drawn.

(1) The simulation results show that through the efficient eco-design of the supply chain, the recycling of solid waste and waste heat can create huge benefits for the coal power and cement plants. The sales revenue of solid waste from the HPTPP can reach over RMB 80 million per year at the highest level. Waste heat and height difference energy power generation can make up 30\% of power consumption of cement plants, and these benefits drive enterprises to positively develop or introduce advanced technology. Meanwhile, the CE system can also contribute to the sustainable 
development of Kongtong through saving mineral resources, reducing carbon emissions, and improving air quality. During 2014-2025, an accumulated total of 14.11 million $t$ of natural gypsum and 22.67 million $\mathrm{t}$ of coal can be saved; as well as reductions in $\mathrm{SO}_{2}$ and dust will reach 22.8 and 13.9 thousand $t$, respectively.

(2) For industrial symbiosis based on the coal power industry, market risks caused by macroeconomics and the tendency of the national energy policy towards clean energy are considered negative factors. Over capacity and heavy losses of upstream enterprises, the serious SDD of recycling waste may further result in the collapse of a CE system. The sustainable development of $\mathrm{CE}$ cannot be separated from effective macro regulation, including the reasonable distribution of industrial symbiosis. Supportive projects, such as China's WEETP and policies of promoting industrial spatial transfer, are crucial in assisting the stability of the CE system of coal power and cement. The introduction of enterprises with intensive uses of power is a feasible way of stimulating local power consumption.

(3) Optimization measures can theoretically further improve the ecological and economic effects. In the future, the heat efficiency of coal power plants, the carbon emission reduction in the cement production process, and the optimization of the denitration equipment are important optimization elements which need to be further studied.

(4) The SD method has high application value in the field of CE research as it can help researchers understand complicated causal associations in the production process of industrial symbiosis and simulate future scenarios through friendly visualization.

(5) The experiences of CE development in Kongtong can be used as a reference for regions with similar industrial structures. Combining cement plants with advanced technology is an effective path to solve the problems of fly ash and desulfurization gypsum pollution and excessive stress on landfill sites.

Acknowledgments: This study is supported by the Key Research Program of the Chinese Academy of Sciences (ZDRW-ZS-2016-6) and The Natural Science Foundation of China (41301637) and the Research Program of IGSNRR (Y5V50013YE). The authors would like to thank leaders and technicians of HPTPP, Conch Cement Ltd., Qilianshan Cement Ltd. and the government staffs of Kongtong District and Pingliang who gave support to authors during field research.

Author Contributions: Suocheng Dong conceived the research idea and designed general framework of the research. Zhe Wang and Fujia Li built SD model analyzed the data, and wrote the paper. Yu Li and Zehong Li. contributed theoretical guidance for the research. Feng Chen and Hao Cheng contributed data collection during field research.

Conflicts of Interest: The authors declare no conflict of interest.

\section{References}

1. Su, B.W.; Heshmati, A.; Geng, Y.; Yu, X.M. A review of the circular economy in China: Moving from rhetoric to implementation. J. Clean. Prod. 2013, 42, 215-227. [CrossRef]

2. Wang, J.N. Circular Economy is a Strategy Choice for Environmental Protection in the 21st Century. Res. Environ. Sci. 2002, 15, 34-37. [CrossRef]

3. Moreno, M.; De los Rios, C.; Rowe, Z.; Charnley, F. A Conceptual Framework for Circular Design. Sustainability 2016, 8. [CrossRef]

4. Andersen, M.S. An introductory note on the environmental economics of the circular economy. Sustain. Sci. 2007, 2, 133-140. [CrossRef]

5. Lu, X; Chen, X.P. A review of circular economy. Chin. J. Popul. Res. Environ. 2014, 24, 204-208.

6. European Environment Agency. Circular Economy in Europe: Developing the Knowledge Base. 2016. Available online: http:/ / www.eea.europa.eu/publications (accessed on 11 July 2016).

7. McKinsey Center for Business and Environment. Growth Within: A Circular Economy Vision for a Competitive Europe. 2015. Available online: http:/ / www.mckinsey.com/business-functions/sustainabilityand-resource-productivity/our-insights (accessed on 13 July 2016). 
8. Kovanda, J. Incorporation of recycling flows into economy-wide material flow accounting and analysis: A case study for the Czech Republic. Resour. Conserv. Recycl. 2014, 92, 78-84. [CrossRef]

9. Wu, H.Q.; Shi, Y.; Xia, Q.; Zhu, W.D. Effectiveness of the policy of circular economy in China: A DEA-based analysis for the period of 11th five-year-plan. Resour. Conserv. Recycl. 2014, 83, 163-175. [CrossRef]

10. Guo, F.Y.; Lo, K.; Tong, L.J. Eco-Efficiency Analysis of Industrial Systems in the Songhua River Basin: A Decomposition Model Approach. Sustainability 2016, 8. [CrossRef]

11. Geng, Y.; Doberstein, B. Developing the circular economy in China: Challenges and opportunities for achieving 'leapfrog development'. Int. J. Sustain. Dev. World Ecol. 2008, 15, 231-239. [CrossRef]

12. Liu, D.H.; Li, H.Y.; Wang, W.G.; Dong, Y.C. Constructivism scenario evolutionary analysis of zero emission regional planning: A case of Qaidam Circular Economy Pilot Area in China. Int. J. Prod. Econ. 2012, 140, 341-356. [CrossRef]

13. Liu, Q.; Li, H.M.; Zuo, X.L.; Zhang, F.F.; Wang, L. A survey and analysis on public awareness and performance for promoting circular economy in China: A case study from Tianjin. J. Clean. Prod. 2009, 17, 265-270. [CrossRef]

14. Li, Y.Z.; Ma, C.Y. Circular economy of a papermaking park in China: A case study. J. Clean. Prod. 2015, 92, 65-74. [CrossRef]

15. Ekincioglu, O.; Gurgun, A.P.; Engin, Y.; Tarhan, M.; Kumbaracibasi, S. Approaches for sustainable cement production-A case study from Turkey. Energy Build. 2013, 66, 136-142. [CrossRef]

16. Oh, D.Y.; Noguchi, T.; Kitagaki, R.; Park, W.J. $\mathrm{CO}_{2}$ emission reduction by reuse of building material waste in the Japanese cement industry. Renew. Sustain. Energy Rev. 2014, 38, 796-810. [CrossRef]

17. Schneider, M.; Romer, M.; Tschudin, M.; Bolio, H. Sustainable cement production-present and future. Cem. Concr. Res. 2011, 41, 642-650. [CrossRef]

18. Supino, S.; Malandrino, O.; Testa, M.; Sica, D. Sustainability in the EU cement industry: The Italian and German experiences. J. Clean. Prod. 2016, 112, 430-442. [CrossRef]

19. Wubbeke, J.; Heroth, T. Challenges and political solutions for steel recycling in China. Resour. Conserv. Recycl. 2014, 87, 1-7. [CrossRef]

20. Zhang, L.; Cai, Z.J.; Yang, J.M.; Yuan, Z.W.; Chen, Y. The future of copper in China-A perspective based on analysis of copper flows and stocks. Sci. Total Environ. 2015, 536, 142-149. [CrossRef] [PubMed]

21. Ma, S.J.; Hu, S.Y.; Chen, D.J.; Zhu, B. A case study of a phosphorus chemical firm's application of resource efficiency and eco-efficiency in industrial metabolism under circular economy. J. Clean. Prod. 2015, 87, 839-849. [CrossRef]

22. Van Buren, N.; Demmers, M.; van der Heijden, R.; Witlox, F. Towards a Circular Economy: The Role of Dutch Logistics Industries and Governments. Sustainability 2016, 8. [CrossRef]

23. Eckelman, M.J.; Chertow, M.R. Life cycle energy and environmental benefits of a US industrial symbiosis. Int. J. Life Cycle Assess. 2013, 18, 1524-1532. [CrossRef]

24. Jacobsen, N.B. Industrial symbiosis in Kalundborg, Denmark-A quantitative assessment of economic and environmental aspects. J. Ind. Ecol. 2006, 10, 239-255. [CrossRef]

25. Shi, L.; Yu, B. Eco-Industrial Parks from Strategic Niches to Development Mainstream: The Cases of China. Sustainability 2014, 6, 6325-6331. [CrossRef]

26. International Energy Agency. World Energy Statistics 2016. 2016. Available online: http://www.iea.org/ bookshop/723-World_Energy_Statistics_2016 (accessed on 22 December 2016).

27. Li, H.Q.; Bao, W.J.; Xiu, C.H.; Zhang, Y.; Xu, H.B. Energy conservation and circular economy in China's process industries. Energy 2010, 35, 4273-4281. [CrossRef]

28. Greenpeace. Research on Overcapacity and Investment Bubble of Coal Power Industry in China. 2015. Available online: http://www.greenpeace.org.cn/coal-power-overcapacity-and-investment-bubble (accessed on 17 February 2016). (In Chinese)

29. Jia, R.X.; Liu, Y. China's power structure and its spatial optimization. Resour. Sci. 2003, 25, 14-19.

30. Zhong, Y.G.; Jia, X.Q.; Qian, Y. System Dynamics; China Sciences Publishing \& Media Ltd.: Beijing, China, 2013; pp. 3-9. (In Chinese)

31. Jahangirian, M.; Eldabi, T.; Naseer, A.; Stergioulas, L.K.; Young, T. Simulation in manufacturing and business: A review. Eur. J. Oper. Res. 2010, 203, 1-13. [CrossRef]

32. Mallick, R.B.; Radzicki, M.J.; Zaumanis, M.; Frank, R. Use of system dynamics for proper conservation and recycling of aggregates for sustainable road construction. Resour. Conserv. Recycl. 2014, 86, 61-73. [CrossRef] 
33. Xu, J.P.; Li, X.F.; Wu, D.S.D. Optimizing Circular Economy Planning and Risk Analysis Using System Dynamics. Hum. Ecol. Risk Assess. 2009, 15, 316-331. [CrossRef]

34. Zhao, W.; Ren, H.; Rotter, V.S. A system dynamics model for evaluating the alternative of type in construction and demolition waste recycling center-The case of Chongqing, China. Resour. Conserv. Recycl. 2011, 55, 933-944. [CrossRef]

35. Mi, G.F.; Zhao, T. Evaluation and prediction of carbon emissions from coal power enterprises in China. Resour. Sci. 2012, 34, 1825-1831.

36. Gartner, E.; Hirao, H. A review of alternative approaches to the reduction of $\mathrm{CO}_{2}$ emissions associated with the manufacture of the binder phase in concrete. Cem. Concr. Res. 2015, 78, 126-142. [CrossRef]

C 2017 by the authors. Licensee MDPI, Basel, Switzerland. This article is an open access article distributed under the terms and conditions of the Creative Commons Attribution (CC BY) license (http://creativecommons.org/licenses/by/4.0/). 